\title{
Energy vulnerability around the world: The global energy vulnerability index (GEVI) ${ }^{1}$
}

\author{
Andrea Gatto*2 Francesco Busato ${ }^{3}$
}

\begin{abstract}
Vulnerability has garnered an increasing attention from academia, international community and industry. Nonetheless, formal definition, mainstreaming, and measurement of vulnerability are still flawed in the economic literature. Energy vulnerability, intended as the exposure of an energy system to adverse events and change, often overlaps with other energy policy concepts such as resilience, security, poverty, justice, and sustainability. This paper improves understanding of vulnerability in economics, energy, and sustainability studies by: i) constructing a dataset on energy vulnerability made of 180.000 observations; ii) formally defining energy vulnerability, while considering the regulatory framework and development agenda; iii) building a composite indicator on energy vulnerability; iv) analyzing and ranking the energy vulnerability of a vast number of OECD and non-OECD countries; v) testing for robustness checks. The analysis suggests that GDP is not necessarily a leading driver for energy vulnerability, whilst resource embedment is, since fossil and renewable energy producers are less vulnerable. Eventually, the paper validates that green countries are less vulnerable, differently from cold, heavily-industrialized, and highlyconsuming countries.
\end{abstract}

\section{JEL classification: C38 C43 O13 Q48}

Keywords: Energy vulnerability Composite indicators Principal component analysis Sustainability Robustness analysis Resilience

\footnotetext{
${ }^{1}$ The authors are grateful to Muhammad Shahbaz, Aviral Kumar Tiwari, Francesco Ricci, Mahdi Majbouri, Fulvio Fontini, and participants at the International Conference on Energy, Finance \& Macroeconomics (ICEFM 2017) in Montpellier, France, Sergio Ulgiati, John M. Polimeni, Tommaso Luzzati, Alessandro Sapio, Francesco Span o and participants at the Biennial InternationalWorkshop Advances in Energy Studies (BIWAES 2017) in Naples, Italy, for stimulating suggestions, and Catalina Crisan, Massimiliano Agovino and Massimiliano Cerciello for skillful discussions and comments that improved the manuscript. The authors must also thank ten anonymous referees that improved the work, as well as Kathleen B. Aviso, assistant editor for the Journal of Cleaner Production, for advice that tangibly helped to upgrade the manuscript, and the Co-Editor-in- Chief of the Journal of Cleaner Production, Cecilia Maria Villas Boas de Almeida, for her support and recommendations. They should also be acknowledged Filomena Maggino, Maurizio Vichi, Anna Rita Manca, Enrico Giovannini, and the auditors of the workshop and tutorial Vulnerability and Resilience: Theories, Methodologies and Applications, University of Rome La Sapienza, Sustainable Development Festival 2018, for the fruitful recommendations provided. The manuscript was improved as well by the advice received from the scientific committee and the participants at the 2018 Energy Community Summer School, Split, Croatia, for bright hints and suggestions, and more particularly: Dirk Buschle, Nigel Jollands, Jasmina Trhulj, Stephen Minas, Adam Balogh, Andrzej Adamski, Marie-Therese Richter, Irina Lazzerini, and Ilija Sazdovski. The paper also benefited from methodological and theoretical support received from Christian Bjørnskov, Martin Paldam, Sven Hylleberg, Niels Strange Grønborg, Luca Neri, Martin Magris, Eric Hillebrand, Bo Sandeman Rasmussen, and participants to the 2018 Seminar Series, School of Business and Social Sciences (BSS) e Center for Research in Econometric Analysis of Time Series (CREATES), University of Aarhus, Denmark. Finally, the authors are grateful to Benjamin Sovacool and Ashley N. Egan for their valuable contribution.

* Corresponding author.

${ }^{2}$ Natural Resources Institute, University of Greenwich, Central Avenue, Chatham Maritime, ME4 4TB, UK. New College of the Humanities at Northeastern University, 19 Bedford Square, Fitzrovia, London, WC1B 3HH, UK. Centre for Studies on Europe, Azerbaijan State University of Economics (UNEC), Azerbaijan. E-mail: a.gatto@greenwich.ac.uk. ${ }^{3}$ University of Naples Parthenope, Department of Economic and Legal Studies (DISEG), Via Generale Parisi 13, Palazzo Pacanowski, Napoli, Italy.
} 


\section{Introduction}

Energy policies devoted to sustainability are in the top agenda of local governments and international institutions. Energy strategies face novel concerns e namely energy poverty, security, justice, and the interconnected notions of energy resilience and vulnerability. Literature increasingly studies and discusses theories and metrics, attempting to measure different dimensions of energy vulnerability.

\subsection{State of the art}

Most of the studies on energy and resources security, vulnerability, and resilience address either industrialized countries (Gnansounou, 2008; Costantini et al., 2007) or less developed countries (LDC) (Morrow et al., 2018; FAO, 2016). For the LDCs, access to electricity is a major concern. Despite improvements in the long-run, 1.06 billion people in the world still lack access to electricity, foremost in rural areas e especially sub-Saharan Africa and South Asia. It is deemed that 20 countries account for 80 percent of the global access deficit in 2014 (IEA and WB, 2017; IBRD \& WB, 2017). Providing universal access to modern energy services by 2030 should be a priority. Moreover, 3.04 billion people rely on solid fuels and kerosene for cooking and heating (IEA and WB, 2017). A controversial challenge comes from the necessity for modern society to cope with the access to modern energy systems with environmental and climate change issues. These aspects related to climate justice received a wide attention in the last years; these were included as development agenda priorities, and enhanced by COP 21 and subsequent climate agreements. In this context, energy strategies such as energy efficiency, $\mathrm{CO} 2$ reduction, GHG emissions containment, and energy transition has taken on a decisive role.

Industrialized countries face energy vulnerability problems as well, also stemming from governance and regulation of natural gas and electricity markets. There is evidence of this since the 2000-2001 Western power crisis and the Enron collapse (Borenstein, 2002). The facts were caused by a series of events, including market abuses operated by Enron and other major players, episodes that are likely to have occurred along a regulatory capture (Busato and Gatto, 2019 \& 2017). In the last decade, further companies were alleged for market manipulation and eventually settled with contested agreements (Markham, 2018) contributing to the sectors vulnerability.

This paper preliminarily defines energy vulnerability as "the degree to which an energy system or entity is more likely to get exposed to adverse events or change, and risks to fall into traps in economic, social, environmental and governance terms" ${ }^{4}$ In this context, resilience has a pivotal role, being a measure for the system, organization, enterprise or entity to adapting and learning from continuous change (Gatto and Drago, 2020a). Long-term sustainability trends are reputed essential to forecast resilience actions (Frankenberger et al., 2012). This must be attributed to the property of the former in affecting livelihood security and exposure to risks and increase vulnerability or adaptive capacity. Being multidimensional concepts, it emerges the goodness-of-fit of composite indicators to define and gauge sustainability dynamics (Joint Research Centre-European Commission, 2008; Nardo et al., 2005).

(Energy) vulnerability assessment is critical for the risk analysis of key infrastructures and resource and to deliver policy recommendations. It passes through vulnerability identification of assets, criticality, and threats (U.S. Department of Energy Office of Energy Assurance, 2002). Energy vulnerability assessment is

\footnotetext{
${ }^{4}$ It is inspiring the definition of vulnerability conceived by Gnansounou (2008): "the degree to which a system is unable to cope with selected adverse events".
} 
also required for establishing preparedness schemes that will ensure effective responses to pulsing challenges e including national strategies to contribute facing climate change, oil price volatility, and overall power sector vulnerability (ESMPAP, 2009).

When it comes to nexuses, it holds the property of resilience to be used as a proxy of energy policy to tackle vulnerability. On the other hand, it results crucial as well the role of sustainability in defining energy vulnerability: vulnerability is related with the dimensions of sustainability, whose balance will configure the upcoming resource tracks (Khan, 2019). Sustainable energy assessments techniques are also employable as early-warning tools for policy design (Ren and Dong, 2018). Vulnerability envisages pathways to formulate resilience policies worthy to draft sustainable development futures (Gatto, 2020) e decisive for modelling public-private partnerships and decision-making strategies (Azapagic and Perdan, 2005).

\subsection{Brief literature review}

The economic literature does not uniquely characterize and perhaps does not offer a clear-cut notion for the concepts of energy vulnerability, resilience, poverty, justice, sustainability, and security (Cherp and Jewell, 2010). Nevertheless, reflexive governance corollary confirm that vulnerability, resilience, and sustainability are closely intertwined (Stirling, 2014). A clear understanding of how these concepts relate to energy policy is needed, especially since the choice of theoretical and methodological framework affects one's interpretation of the results (Sovacool, 2011; Kruyt et al., 2009; Winzer, 2012). It is worthwhile to apply this assertion to energy vulnerability, underscoring the need to define and measure a topic that remains not sufficiently delineated in the literature.

Energy is a leading driver of economic growth, employment, and sustainable development. Energy policy is a major development agenda area of action. Ensuring energy services for all is recognized as a core strategy to tackle poverty and reach energy security itself. The implementation of a modern, affordable, reliable, sustainable, and universal energy access should be among the pre-requisites for enabling virtuous economic cycles. Such access would eventually alleviate poverty, contribute protecting the environment, and building solid institutions (UN, 2015).

In September 2015, the UN launched the Agenda 2030. Within the 17 Sustainable Development Goals (SDGs), vulnerability and resilience policies play a leading role. On the other hand, energy policy was addressed through a whole Goal: SDG 7 requires to "ensure access to affordable, reliable, sustainable and modern energy for all" (UN, 2015). As part of SDG 7, they were detected 5 targets and 6 indicators with specific energy policy scopes, to be achieved by 2030. Target 7.1 proposes to "ensure universal access to affordable, reliable and modern energy services", while Target 7.2 states to "increase substantially the share of renewable energy in the global energy mix". For Target 7.3, it was agreed to "double the global rate of improvement in energy efficiency", and for Target 7.A, the consensus was based on "enhance international cooperation to facilitate access to clean energy research and technology, including renewable energy, energy efficiency and advanced and cleaner fossil-fuel technology, and promote investment in energy infrastructure and clean energy technology". The latter relevant target, 7.B, focused on "expand infrastructure and upgrade technology for supplying modern and sustainable energy services for all in developing countries, in particular least developed countries, small island developing States, and landlocked developing countries, in accordance with their respective programs of support". 
Energy regulation affects energy vulnerability as well, since history observed energy price manipulation schemes ran across the regulation scheme. With the scope to merge national markets into a unique European energy market, the European Commission (EC) saluted a set of reforms, aiming at enhancing supply security, environmental sustainability, production efficiency and market competitiveness (Gnansounou, 2008). In regulatory terms, in the last years the EU showed to be proactive when it came to energy security regulation, implementing a series of directives and Green Papers through the EC (EC, 2001a, 2001b, 2003 \& 2006). The 2000e2001 US energy crisis led to a further EU regulation e the Regulation on Wholesale Energy Market Integrity and Transparency (REMIT); this aimed defending the energy markets from the risk of detrimental insider trading, market manipulation and wholesale energy markets transaction (EU, 2011).

Among the most recent EU actions, one must mention the circular economy transition package, adopted on 2 December 2015 by the EC and approved in March 2019. This industrial model foresees a new role for products and materials, passing from a linear to a circular life path. Circular economy conceives a fundamental role for energy turns: waste and resources are minimized and valorized, with the sake of stimulating innovation, growth, and occupation in a sustainable development vision (Gatto et al., 2017; Ghisellini et al., 2016).

To complete the picture, there is an additional stream of research focusing on indicators on energy policy; these studies explored grassroots vulnerability and resilience, energy poverty, sustainability, justice, and security. Energy vulnerability also received some attentions, especially concerning the supply side. Typically, the analyses propose a simple and/or composite indicator to measure the phenomena. Though both the definition and the calculation of energy vulnerability remain not completely covered and ambiguous. The most recent indexes generally convey in attributing a crucial role to sustainability. Among the many, Patlitzianas (2008) and Badea (2010) offer a comprehensive review of various indicators, methods, and objectives, focused on sustainable energy policy.

Given these premises, this paper offers the following contributions: 1) construction of a fully-fledged time series database collecting 12 measures of energy vulnerability for 265 countries worldwide (OECD, nonOECD countries, regions, and territories), for over 57 years (approximately 180.000 observations); 2) the definition of a conceptual framework capable to accurately define the notion of energy vulnerability; 3 ) the construction of a robust composite indicator on energy vulnerability (global energy vulnerability index, GEVI), considering selected dimensions of sustainability (i.e. economy, society, environment, governance) ${ }^{5}$; 4) the analysis of GEVI performance over the collected data, while discussing country rankings and selected policies; and 5) the regulatory and development agenda analysis.

The paper proceeds as follows. Section 2 presents the Index from a methodological perspective, together with collected and used data; Section 3 comments the main results, while Section 4 discusses the paper in relation to the existing literature to justify the novelty of the contribution. Section 5 concludes. Appendixes $A, B$, and $C$ present the multivariate analyses and the country pillarprofiles, run for interested readers.

\section{Data and methodology: the global energy vulnerability index (GEVI)}

The paper proposes a global energy vulnerability index constructed following methodological steps suggested in the JRC-OECD Handbook of Composite Indicators (Joint Research Centre- European

\footnotetext{
${ }^{5}$ As in Meadows et al. (1972).
} 
Commission, 2008). Table 1 below sketches the methodological procedures undertaken to construct the GEVI. Table 2 eventually summarizes the structure of the GEVI Index.

\section{Results}

The variables define the notion of energy vulnerability in all four dimensions of sustainability (Meadows et al., 1972). The methodology is in line with existing Energy Vulnerability Index (Gnansounou, 2008): the new index relies on four out of five variables from the former index (Energy Intensity of the GDP, Energy Import Dependency, Energy-related CO2 emissions against TPES, Electricity supply vulnerability, and Non-diversity of transport fuels). The index does not include the variable "Non-diversity of transport fuels", used by Gnansounou. Two remarks arise. This work might improve upon currents analysis schemes to detect a further governance variable e though no governance variable is included in the WDI dataset. This presumptive flaw was addressed encompassing the governance dimension of sustainability in most of the variables as a secondary dimension. Another fact to be pointed out is that several variables display different signs in terms of partial ranking, signaling that polarity is a decisive information to be evaluated in the following methodological steps.

Next figures present the selected dimension of the index. Following composite indicators literature, Fig. 1 below plots the ten top, ten middle, and ten bottom countries from the energy vulnerability ranking, emphasizing the partial results of the seven GEVI pillars. For a graphical analysis of the singular pillars scores, one can refer to Appendix B. The rationale was to realize a comparative international analysis, assembling a set of best, average, and worst performers, useful to capture national classifications, keeping an eye on the pillars scores. 


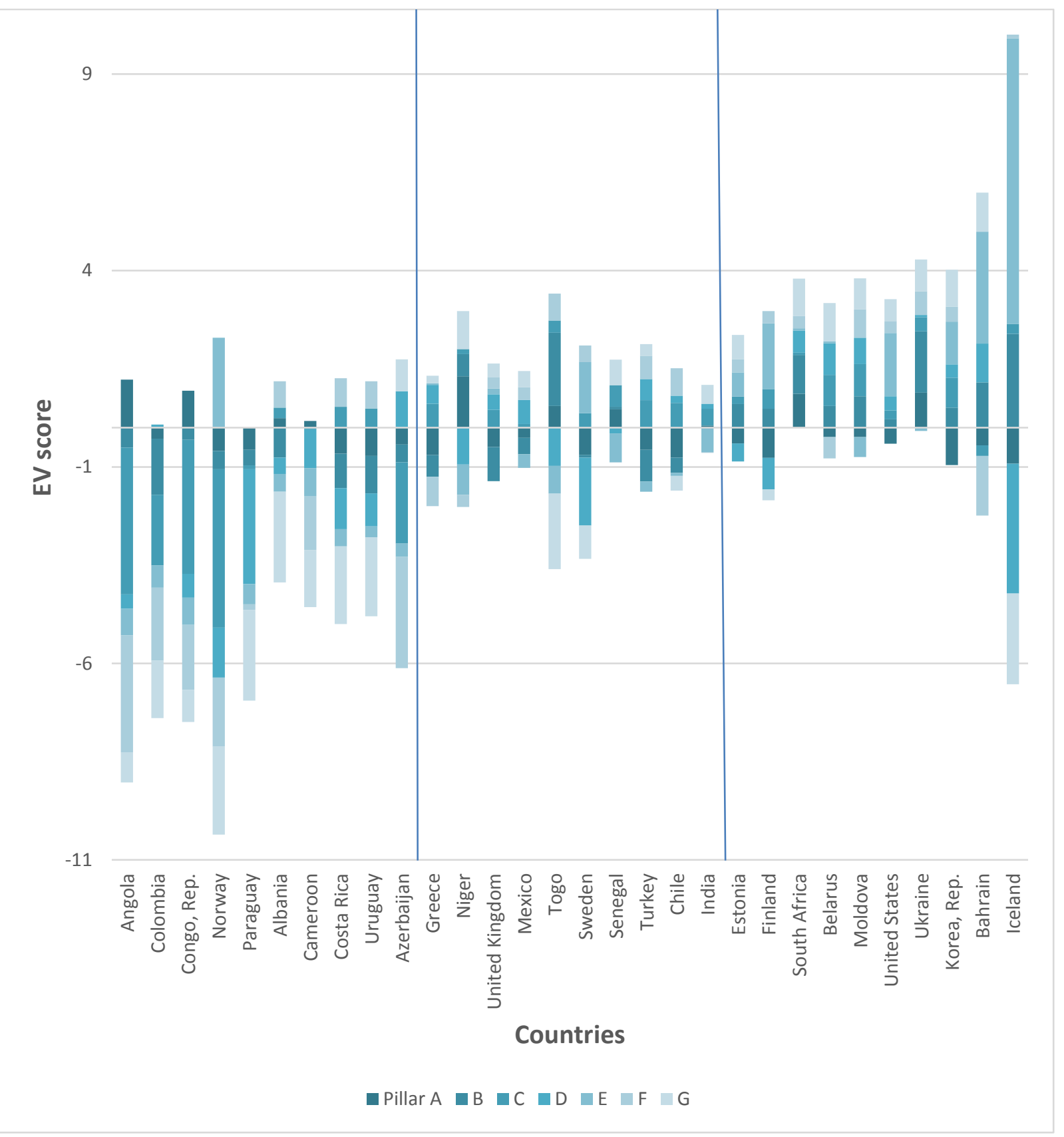

Figure 1 - Country performance for pillars

Fig. 2 next, completes Fig.1 picture, presenting a spider diagram of the seven GEVI pillars for selected countries; these are representative of the different world regions, climates, development stages, energy production, and consumption and environmental attitudes and attributes. 


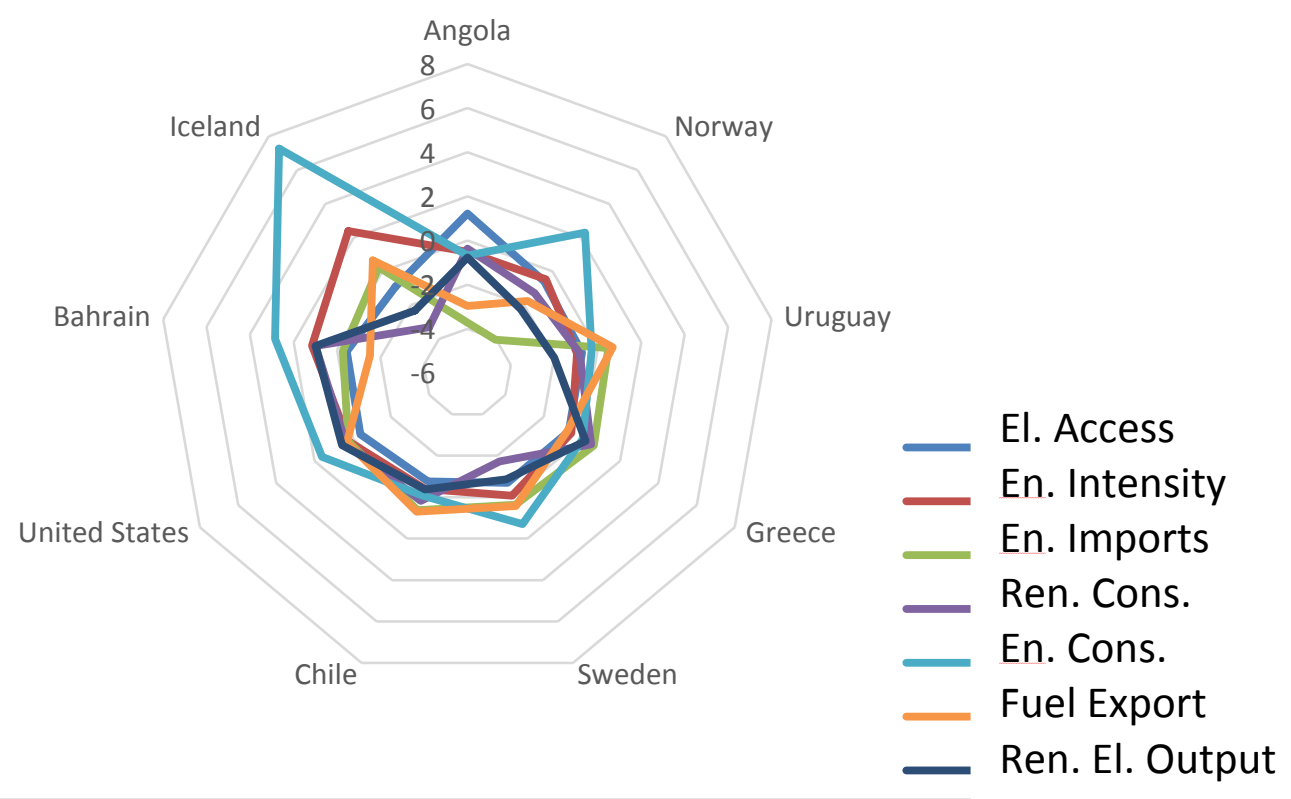

Figure 2 - Spider diagram GEVI

The most vulnerable country e Iceland e displays a significant heterogeneity in the performance of the single pillars: highly differentiated results amongst the different variables emerge: Iceland performs extremely poorly in pillars like energy consumption whilst for renewable energy consumption shows outstanding records. The best performer - Angola - takes advantage of an interesting result, due to oil production, modest consumption, and an overall good performance for each indicator. More details regarding the pillars' differentials are presented in Appendix C.

Whilst existing studies focus on developing countries - more precisely samples from rural villages families (FAO, 2016), or on a set of specific industrialized countries (Gnansounou, 2008), this paper offers a global representation of the phenomenon at a macroeconomic level.

Table 1 eventually summarizes the structure of the GEVI Index.

\section{Table 1 - Methodological procedures and rationale of the GEVI}

1 Theoretical and conceptual framework (see Section 1 - Introduction).

2 Data selection: The proposed index is based on 2017 WB'sWDI data on Energy (World Bank, 2017). It is built up a dataset consisting of 265 country observations from 1960 to 2016, over twelve variables. From this dataset, this paper proposes a cross section over the most recent year displaying consistent data (i.e. the wider sample), namely 2014. 
Variables related to investment in energy with private participation and ores and metals exports were dropped from our sample since these variables are not in line with the definition of energy vulnerability, while being not capable to add significant information, not pertaining to the field, nor matching the criteria behind the indicator proposed.

A total of 7 pillars with 12 sub-pillars have been encompassed in the GEVI.

Selected relevant variables were collected from the 2017 edition of World Development Indicators issued by the World Bank. The collection was based on the variables from Energy \& Extractives Open Data Platform. The 7 pillars detected for the index scope come from the WB's Energy \& Mining featured development indicators, that provide variables related to energy policy on economic, social, and environmental dimensions worldwide. Indicators come from different sources, i.e. internal (WB), external and mixed. Each indicator has different records, showing some divergences in data collection in terms of countries and time series.

It is possible to examine the chosen variables and pillars, with regards to the four sustainability dimensions that forged the research's theoretical framework e societal, economic, environmental, and governance. The motivations of the data selection are pitched below.

- Electricity access (measured by the variables access to electricity and time to get electricity) was chosen as a major requirement to tackle energy vulnerability, a prior for societal needs.

- Energy intensity, given by the relationship amongst Total Primary Energy Supply and GDP, has been coupled with GDP per energy use. They express national energy efficiency, where a high rate of energy intensity or GDP per energy use displays high substitution costs of energy into GDP.

- Energy import is determining for energy trade. In this sense, a country that relies on energy imports has been considered as more likely to be vulnerable.

- The pillar $D$, renewable energy consumption, is composed of three sub-pillars: renewable energy consumption, alternative and nuclear energy, and fossil fuel consumption.

Considering that a cleaner consumption is associated with a lower vulnerability, the first two variables have been accounted of impacting negatively on energy vulnerability, whereas the polarity of the third was positive (affecting the environmental dimension, hence increasing vulnerability).

- A greater energy consumption (here composed by electric power consumption and energy use) is associated with greater energy requirements and pollution, affecting both the economic and environmental sphere.

- Fuel export is a determinant of one country's power embedment, signaling decreased vulnerability.

- Renewable energy output is considered to smooth energy vulnerability, being a channel for energy sources diversification.

3 Data treatment: The dataset built consists of more than 180.000 observations. Considering the vast content of the dataset, they were evaluated several techniques options for the treatment of the missing values. As recommended by the literature for similar cases (Joint Research Centre-European Commission, 
2008), the work proceeds with data deletion, eliminating the observations for which 2014 was not reported. It must be noted that this decision consented to achieve a parsimonious result: they were mainly discarded data relative to regions and territories, while most of the countries were preserved. This decision allowed to keep 146 countries, representative of the vast majority of world population. Alternative methods that were evaluated for data imputation were hot and cold-deck imputation, mean/median substitution, and regression imputation for single imputation. On the other hand, the use of Monte Carlo Markov Chain (MCMC) was assessed as for multiple imputation. ${ }^{6}$

4 Normalization: The standardization of the indicators was necessary to make them comparable; then Zscores were run.

5 Weighting and aggregation: After standardizing the values to make them comparable, it is used a weighted sum, using equal weights, to make a linear aggregation and compute the seven sub-pillars chosen - somehow representative of diverse energy dimensions. Having aggregated the twelve sub-pillars into seven pillars, the computation proceeded reducing the dimensions of the pillar into the synthetic index.

6 Multivariate analysis: Next, it is performed a Principal Component Analysis (PCA) as a multivariate analysis method to calculate the final index, the GEVI. PCA was performed to further reduce the dimensions of the pillars. The PCA is employed with the aim to reduce the number of variables in latent variables. PCA was employed to obtain factors explaining correlations among variables; thus, high correlations must be displayed. They are examined the outcomes of eigenvalues and explained variance, fixing a threshold for the two factors for the explanation of the total variance. Each factor is weighted by each eigenvalue, that gives a ranking. For the multivariate analysis, it was first examined the correlation matrix (see Appendix A, Table 4 - Correlation matrix) among the pillar variables significance, where they were run both the correlations between the 12 starting variables and the one-tail significance. The correlation matrix among the pillar variables significance exhibits few high correlations, as it is suitable. The correlation matrix was completed by plotting its inverse (see Appendix A, Table 5 - Inverse correlation matrix) to verify that correlations among pillars are significant. Thus, they were run a Kaiser-Meyer-Olkin (KMO) test - measure of sampling adequacy -, and a Bartlett's sphericity test, in order to evaluate the feasibility of the PCA for the analysis (see Appendix A, Table 6 - KMO and Bartlett's tests). As it can be seen from Appendix A, the Chisquare results of Bartlett's sphericity test confirms the validity of the outcoming, allowing to proceed in the exercise. Since the aim is to obtain factors that explain correlations among variables, the former must display high correlations. The exercise accounts for the values of eigenvalues and explained variance. Thus, it is fixed a threshold for the two factors for the explanation of the total variance. Each factor is weighted by each eigenvalue, that gives a ranking. Hence, they are examined the pillars communalities - extracted through the PCA (see Appendix A, Table 7 - Communalities). Pillars communalities suggest extracting four principal components. These outputs were consolidated graphically, representing a scree plot (see Appendix A, Fig. 5 - Scree Plot). The results sketched are confirmed by the scree plot. The Kaiser criterion recommends dropping factors with eigenvalues $<1.0$ (Nardo et al., 2005). The aim is to preserve

\footnotetext{
${ }^{6}$ In these regards, switching models for latent variables might be useful to detect the changing regimes in the business cycles and the relationship between energy crises and business cycles turning points - more precisely, that oil shocks affect the likelihood to enter a recession e (Engemann et al., 2011).
} 
cumulative data, selecting the first components. The analyses suggest that variability across all factors is best captured in four principal components as can be observed in the appendixes. The results are confirmed by the scree plot also reported in Appendix A.4

More analyses were run to corroborate those tests. They were analyzed the component matrix (see Appendix A, Table 8 - Components matrix) of the 9 pillars that extracts 4 components through the PCA, the correlations reproduced - making use of the PCA - between the 9 pillars (see Appendix A, Table 9 Correlations reproduced). The tests allow to check for both the correlation reproduced and the residual. The study eventually provides a rotated component matrix (see Appendix A, Table 10 - Rotated components matrix) and a component transformation matrix of the 9 pillars (see Appendix A, Table 11 Component transformation matrix), that in this case are worthwhile to be extracted exploiting the PCA and rotated through varimax with Kaiser normalization (Nardo et al., 2005).

7 Uncertainty and sensitivity analysis: Next, to check robustness, different weighting and aggregation schemes are computed. The goodness-of-fit of the choices was thus checked by a correlation exam between the final results/techniques adopted. Its results are presented below. This is a fundamental step to validate the exercise soundness (Drago and Gatto, 2018; Nardo et al., 2005). The following tests have been ran: i) an equal weight estimate, ii) a subjective weight based on the dimensions of sustainability (economic, social, environmental, and governance dimensions, Meadows et al., 1972), iii) and a data aggregation through the Borda method. Along these dimensions, the work aims to match the qualitative and the quantitative approach, giving a rigorous and objective rationale to define and measure the notion of energy vulnerability.

8 Relation to other indicators (see Section 4 - Discussion).

9 Decomposition into underlying indicators data representation, rankings, and comparisons between results are presented. Next, the different variables, pillars, and geographical areas are estimated. The exercise is completed making use of a set of techniques for data communication, as for diagrams, heat maps, and tables. A full discussion and representation are presented in Sections 3, 4 e Results, Discussion.

10 Visualization (see Section 3 - Results)

Table 2 - GEVI: pillars and sub-pillars.

Global Energy Vulnerability Index (GEVI)

PILLAR

SUB-PILLAR

A - Electricity access

A.1) Access to electricity 
B - Energy Intensity

C-Energy imports

D - Renewable Energy

Consumption
B.1) Energy Intensity

B.2) GDP per energy use

D.1) Renewable Energy Consumption

D.2) Alternative and Nuclear Energy

D.3) Fossil Fuel Energy Consumption

E - Energy Consumption

E.1) Electric Power Consumption

E.2) Energy Use

F-Fuel Export

G - Renewable Electricity

Output

The analysis on developing countries furnishes a relatively more accurate overview of resilience concept, dealing mostly with the household component, interpreted as the center of resilience decision-making (FAO, 2016). Technically, this purpose is obtained through a survey, making use of a rotating panel for a number of Ugandan families. Some remarks raise. The years involved in the analysis are typically few (two years for each of the two samples of families, totally four years). This work benchmarks for the definition and measurement of (food) resilience and its policy implications; despite its scientific relevance, its methodology may want to benefit from an enhanced robustness for analyzing the rotating panel assessed. This is especially due to the reduced number of families surveyed, their localization - a circumscribed remote area e, and the limited time-span during which they are observed. Potential mistakes in calculation 
might lead to the risk of a wrong interpretation and dissemination about what a shock is and how to cope with resilience measures. Corroborating the methodology and the data collection seems to be a useful step to give a complete view of resilience and to ensure the exercise replicability. This result can be achieved by testing or comparing the technique adopted with other methodologies within a sensitivity analysis and their correlations exam. The tests could eventually decrease the potential variables multicollinearity and discharge the index from falling into a potential case-based spectrum; this would yield a more reliable composite indicator in line with the demanding scientific and policy requirements (Gatto and Drago, 2020b, Drago and Gatto, 2018; Agovino et al., 2018).

Studies focusing on a set of industrialized countries use IEA data to give a supply-side glance of energy vulnerability (Gnasounou, 2008). There are several lessons that can be learnedfrom this work. Namely: i) the subjectivity of the choice in weighting the pillars composing the index; and ii) the number and variance of the set of selected countries (25, all OECD countries). The index has been applied in World Energy Council's Europe's Vulnerability to Energy Crises (2008). Compared to 2005 IEA Statistics, 2017 WDI energy data seems to be more appropriate displaying longer, more accurate, updated, and detailed time series, succeeding in catching the energy-development nexus. Gnansounou's index presents the great merit to provide a preliminary definition of energy vulnerability, clearing the path to further research. Another good point is that, methodologically, the work prescribes the use of a Euclidean distance to the benchmark country. Though the use of subjective weighting, coupled by the lack of a robustness check and/or a sensitivity analysis, stimulates to enhance the research methodology and to pursue a further energy vulnerability index.

Fig. 3 sketches the GEVI results on all the pillars. Top ten, middle ten, and bottom ten ranked countries are represented, from left to right, according to scores. The results might seem somehow surprising: among the best worldwide performers (displaying a lower vulnerability), they can be found deeply diverse countries, e.g. Angola (last energy vulnerable country), Colombia, Republic of Congo, Norway, Paraguay, Albania, Cameroon, Costa Rica, Uruguay, and Azerbaijan. On the other hand, it is noticeable Iceland (most energy vulnerable country), Bahrain, Southern Korea, Ukraine, United States, Moldova, Belarus, South Africa, Finland, and Estonia, as the most energy vulnerable worldwide countries. 


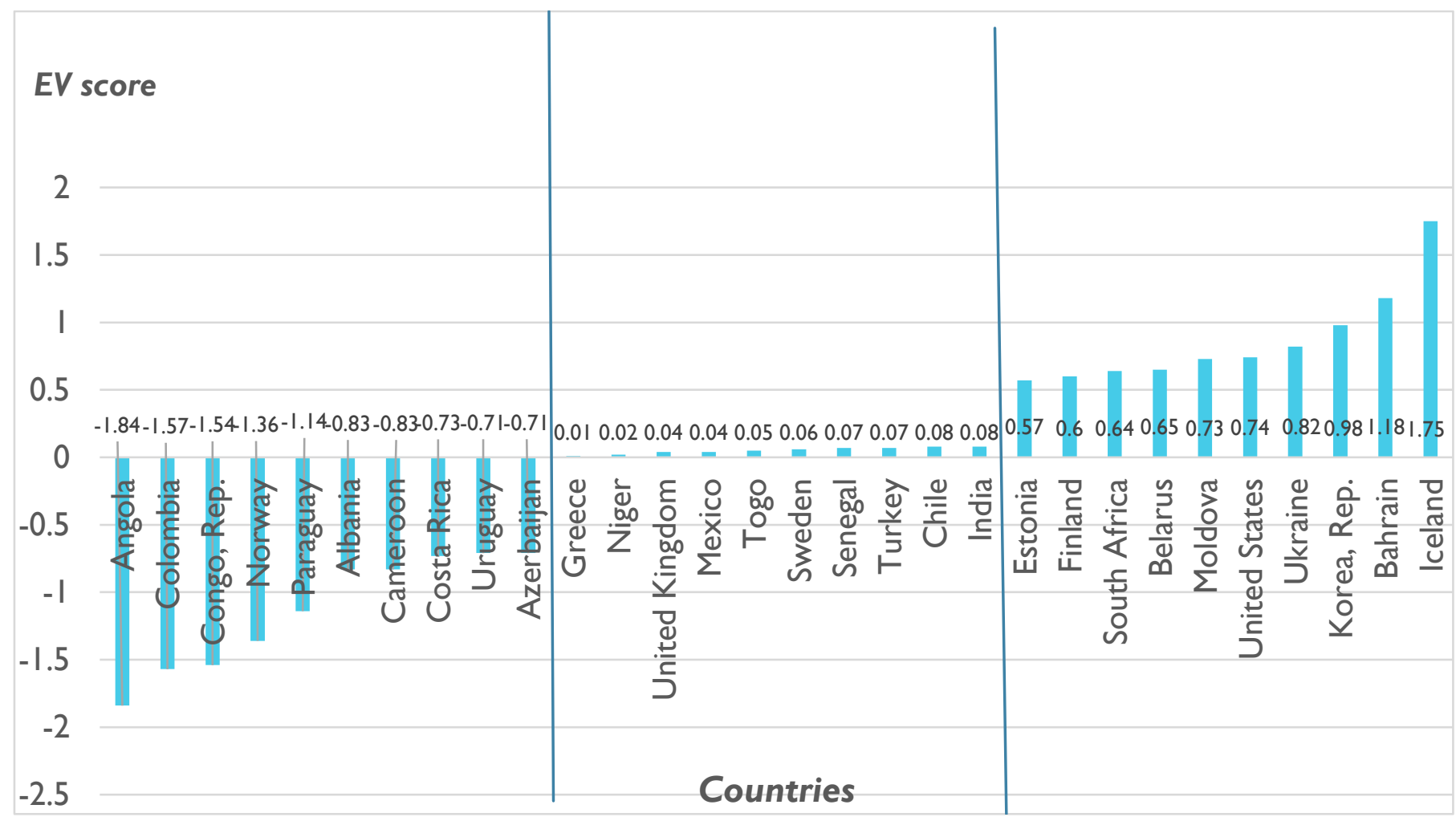

Figure 3 - Ranking GEVI

The results discussed formerly are represented on a map in Fig. 4, catching a global picture of energy vulnerability. It is not observable a geographical clustering, signaling that leading factors are not solely determined by their location or geographical attributes, whereas a combination of those factors and especially natural embedment seem to be more important in terms of energy vulnerability. As for Fig. 1, the choice fell into a worldwide comparative analysis, useful to underpin selected national performances.

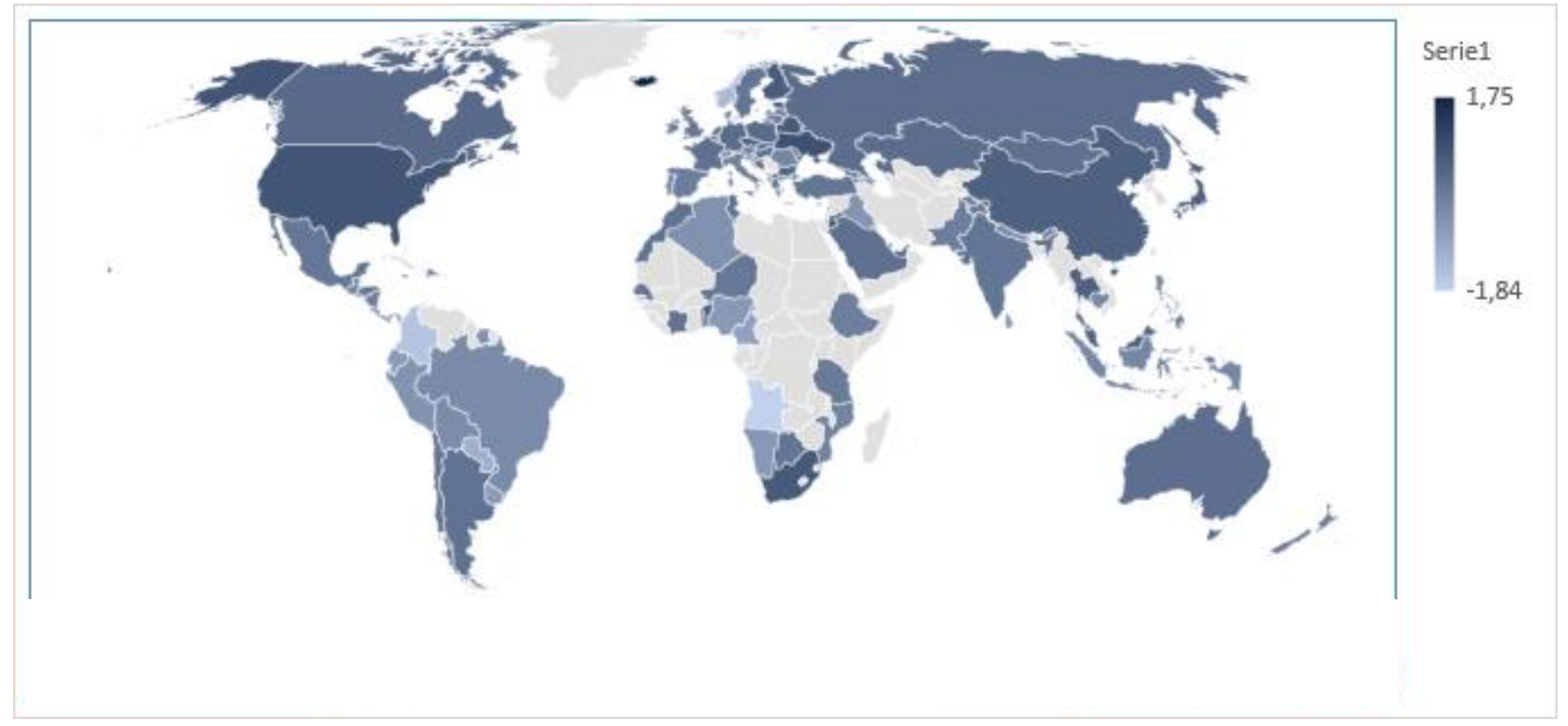




\section{Discussion}

Other indexes inspired the chosen strategy, formulation, and conceptual framework. Energy vulnerability in coal mining industrial ecosystem is measured by Wang et al. (2017). The resulting benchmark index aims at evaluating the framework of energy prices volatility, whereas sustainable development is related to regional development. The index sorts 14 pillars and 33 coal mining areas in China, whilst methodologically exploits rough set technique for order preference by similarity to ideal solution rank- sum ratio.

The bridge between energy policy issues e and more specifically the security-vulnerability nexus e is thoroughly examined by Kendell (1998). Imports are gauged in terms of vulnerability and applied to the oil sector, localizing the exercise to the United States. Hence, import vulnerability is deemed a proxy for energy security performance.

Other papers deal with environmental vulnerability, applied to resource economics issues e namely, agroindustrial innovations (de Figueiredo et al., 2010). In this case, the environmental performance is appraised by calculating an indicator that measures the vulnerability analysis of watersheds. Hence, the study adopts the Ambitec-Life Cycle method. Then, the environmental vulnerability index is run, taking into consideration the life cycle stages, as defined in the paper. Ten environmental policy issues are taken into account, and seventeen pillars are considered for the criteria of exposure, sensitivity, and capacity of response.

The index on which this study mainly relies theoretically is the synthetic index of energy demand/supply weaknesses defined as a proxy of energy vulnerability (Gnansounou, 2008). Built on five indicators, the index explores the dimensions of energy policy sustainability to detect vulnerability drivers in the EU and OECD countries. The weighting rationale is based on subjective choices, a possible methodological limitation. Albeit this potential flaw in the index composition, the work presents the benefits of advancing a statistic root, exploiting the Euclidean distance to the benchmark country e a choice that increases the index robustness.

Another vulnerability index, pitched to energy crises and applied to Europe, has been gauged by the World Energy Council (WEC, 2008). This index focuses on both the demand and the supply side and associates the vulnerability with the risk. It takes into account the sustainability dynamics. In Percebois (2007) as well, the risk has a leading role in determining what energy vulnerability consists of. As for the index proposed in this paper Percebois attributes a leading role to regulation. Differently from this paper, in the latter regulation accounts for price volatility, variations in exchange rates and risk of blackouts which occur within the electricity sector. In addition to these factors, the index embeds industrial, trade and technological variables, paying attention to distinguish energy vulnerability from energy dependence.

As in Gupta (2008), this work employs a multivariate analysis, i.e. the PCA, to weigh the nine variables employed in the four pillars and hence examine the countries. The PCA merges the simple indicators, already aggregated into seven pillars, to form a synthetic index, ensuring an increase in robustness and objectivity with respects to subjective choices. Thus, the exercise makes use of Borda rule, subjective weights and equal weights to corroborate the results obtained, controlling as well for the correlations among each other results. In terms of methodology, the energy vulnerability index that seems to be more in line with the gauging choice selected here is the Oil Vulnerability Index (Gupta, 2008). This index focuses 
solely on the oil sector. It is based on a set of seven indicators and presents the strength of the principal component analysis (PCA) weighting. The multivariate methodological approach of the principal component technique has been adopted to combine these individual indicators into a composite index of oil vulnerability to measure the complex phenomena. Such an index captures the relative sensitivity of various economies towards developments of the international oil market, where a higher index indicates higher vulnerability. The work relaxes on a crosssection analysis over 26 net oil-importing countries. It aggregates as indicators oil trade and consumption with respects to GDP, oil reserves, dependence, and sources, as well as political risk and market liquidity. The results show that there are considerable differences in the values of individual indicators of oil vulnerability and overall oil vulnerability index among the countries (both inter and intra-regional).

The paper presented is based on the time series reconstruction for a dataset that evaluates the energy vulnerability of 265 countries; this consists of the totality of worldwide OECD and non-OECD countries, regions, and territories. The proposed index developed in this work takes into consideration the four dimensions of sustainability (economic, social, environmental, governance). ${ }^{7}$ The dimensions are incorporated into seven pillars and then into twelve sub-pillars. For such scope, the 2017 WB's WDI dataset on Energy and Mining is exploited. A sorting of countries with respects to energy vulnerability is eventually provided. Therefore, selected policy implications are discussed to clear the path to the nexus with energy resilience and its policies.

\begin{tabular}{|c|c|c|}
\hline Index & Phenomenon & Method/rationale remarks \\
\hline $\begin{array}{l}\text { Energy security-energy } \\
\text { vulnerability nexus } \\
\text { (Kendell, 1998) }\end{array}$ & Oil import vulnerability in US & $\begin{array}{l}\text { Import vulnerability as a proxy of } \\
\text { energy security performance }\end{array}$ \\
\hline $\begin{array}{l}\text { Energy vulnerability index } \\
\text { (Gnansounou, 2008) }\end{array}$ & $\begin{array}{c}\text { Energy demand/supply weaknesses as a } \\
\text { proxy of energy vulnerability in EU and } \\
\text { OECD countries }\end{array}$ & $\begin{array}{l}\text { Subjective weighting but Euclidean } \\
\text { distance to the benchmark country }\end{array}$ \\
\hline $\begin{array}{l}\text { Europe's vulnerability to } \\
\text { energy crises } \\
\text { (WEC, 2008) }\end{array}$ & Focus on both demand and supply & $\begin{array}{l}\text { Vulnerability associated with energy } \\
\text { crises risk. Sustainability is considered }\end{array}$ \\
\hline $\begin{array}{l}\text { Energy vulnerability } \\
\text { management } \\
\text { (Percebois, 2007) }\end{array}$ & $\begin{array}{l}\text { Focus on electricity regulation. Price } \\
\text { volatility, variations in exchange rates and } \\
\text { risk of blackouts appraised }\end{array}$ & $\begin{array}{l}\text { Energy vulnerability is distinguished } \\
\text { from energy dependence }\end{array}$ \\
\hline $\begin{array}{l}\text { Oil vulnerability index } \\
\text { (Gupta, 2008) }\end{array}$ & Vulnerability in the oil sector & Principal component analysis \\
\hline $\begin{array}{l}\text { Coal mining industrial } \\
\text { ecosystem Vulnerability Index } \\
\text { (CVI) } \\
\text { (Wang et al., 2016) }\end{array}$ & Vulnerability in the coal mining sector & $\begin{array}{l}\text { Rough Set-Technique for Order } \\
\text { Preference by Similarity to Ideal } \\
\text { Solution-Rank-sum Ratio }\end{array}$ \\
\hline $\begin{array}{l}\text { Global Energy Vulnerability } \\
\text { Index (GEVI) } \\
\text { (Gatto \& Busato, 2019) }\end{array}$ & $\begin{array}{l}\text { Worldwide energy vulnerability - } 12 \\
\text { indicators on economic, social, } \\
\text { environmental, and governance dimensions } \\
\text { of energy policy }\end{array}$ & $\begin{array}{c}\text { Principal component analysis } \\
\text { corroborated by a robustness analysis } \\
\text { on weights (subjective and equal } \\
\text { weights), and aggregation (Borda } \\
\text { Rule) }\end{array}$ \\
\hline
\end{tabular}

Table 3 - Energy vulnerability indexes

\footnotetext{
${ }^{7}$ As in Meadows et al. (1972).
} 
Along these dimensions, the paper contributes to the energy policy debate through the following scientific purposes: i) defining energy vulnerability; ii) measuring energy vulnerability; iii) ranking energy vulnerability globally. Further contributions of the paper regard the reconstruction of the time series on energy vulnerability variables, the assessment of the regulatory framework on energy vulnerability and the examination of WB's WDI data on Energy from OECD and non-OECD countries. Table 3 above resumes the energy vulnerability indexes explored in this paragraph.

The GEVI contribution with regard to existing indexes is twofold: first, it furnishes a measure of energy vulnerability whole worldwide countries, regions, and territories, on a broad range of policy variables. Second, the GEVI provides a sound theoretical, data, and methodological framework, corroborated by a set of uncertainty analyses.

These outcomes suggest entangling a parallel outlook: besides the general ranking, one should take into account the single pillars scores. This favors clearer national economic implications and policy intuitions and motivates the implementation of a two-level composite indicator. Iceland represents an interesting case, resulting as the most vulnerable country in terms of energy consumption, and less vulnerable when it comes to renewables consumption.

Iceland can be used as a case study: the large differences remarkable in the scores of its pillars are due to diverse factors, above all: the national energy mix, the industrial structure, the domestic cold climate, and the country's remote location. On one hand, the geothermal and hydroelectric sources ensure to Iceland to exploit some $98 \%$ of renewable energy on the overall consumption, being Iceland energy greenness a notable economic fact amongst development and energy practitioners. On the other hand, Icelandic industry requires a lot of energy. Apart from paper, steel, heavy and polluting industries, it is peculiar the role played by Icelandic fisheries e often showcased for its sustainable and CSR attributes. Though, all these industries, are greatly energy demanding e also in light of the country's remoteness e and call for large energy vulnerability.

Looking at the big picture, Iceland allows for more analyses if one relax on the regional performances. In this sense, the Nordic region is paramount: it classifies greatly non-vulnerable (Norway), highly nonvulnerable (Denmark), average vulnerable (Sweden), highly vulnerable (Finland), and greatly vulnerable (Iceland) countries. This fact is mostly motivated from the diverse national resource embedment, industry structure, and location. The outcomes from the principal component analysis are corroborated by the adoption of an uncertainty analysis. The study made use of an additional aggregation technique, i.e. the Borda ranking rule, and two further weighting schemes, namely equal weights, and subjective weights grounded on a sustainability rationale. The results yield by the sensitivity analysis confirm the methodological goodness-of-fit.

Perspective policy implications arise: a resilience approach seems to be strictly connected with energy vulnerability. Energy resilience measurement relies often on the household as the center of decisionmaking, being families focal for first resilience responses to face vulnerability. Resilience policies are becoming foremost in the energy sector: one can mention remittances and microfinance tailored programs, often aiming to the encouragement of mini-grid and other energy access facilitation, showed to effectively decrease the vulnerability status, empowering energy resilience, justice, and security, fighting energy poverty. These trends, combined with the findings of this work, confirm the importance of keeping a tight interconnection between the economic, social, environmental, and governance sustainability. The holistic approach promoted by the international development agenda is paving the way for a mark towards cleaner energy production systems and eventually benefit from it. 


\section{Conclusion}

This paper defines, measures, and ranks worldwide energy vulnerability, addressing the increasing need to understand global vulnerability and resilience, also for energy policy scopes. The work contributes to the literature building a tailored composite indicator, on the basis of 2017 WB's WDI on Energy and Mining, called global energy vulnerability index (GEVI).

The paper contributes to the knowledge on energy and resource vulnerability definition and measurement. The principal benefits are the construction of a broad dataset entangling energy policy variables, and the conceptualization, gauging, and ranking of international energy vulnerability. The results can be discussed from a policy perspective, whereas the methodological choices have been shown their robustness. The work offers insights for future research discussions in the energy policy, sustainable development, and composite indicators literature. Further research might include a focus on different (wider) use of the constructed dataset and methodologies diversions: for example, panel data analyses to detect the underlying long run trends, or further missing values treatment, that imply germane data imputation implications.

Original model predictions emerge. The analysis proves that the GDP is not necessarily a driver for energy vulnerability, while representing a leading asset for resilience measurement. This apparently counterintuitive figure is also confirmed from the fact that cold, highly consuming, inefficient, and heavyindustry-led countries are in the first positions in both energy vulnerability and resilience indexes (e.g. Iceland), while oil producing, scarcely consuming, warm, non-industrial countries, rank often as last in both types of indicators (e.g. Angola).

It is, next, validated that resource endowment matters. Energy producers (both fossil and renewables exporters) display on average a lower vulnerability, explained from the fact that they are the least exposed countries to the risk of lacking energy resources. The paper, then, confirms that greener countries display better results, performing well in renewables consumption. Countries lacking in electricity access present generally a high vulnerability, confirming that energy access is still a strong player of energy vulnerability.

The development agenda forged the work's research rationale in proposing to define and calculate energy vulnerability worldwide, examining energy resilience and sustainable development regulation. Though the success of policymaking relies primarily on the right definition and metrics of complex phenomena. 


\section{References}

Agovino, M., Cerciello, M., Gatto, A., 2018. Policy efficiency in the field of food sustainability. The adjusted food agriculture and nutrition index. J. Environ. Manag.

Azapagic, A., Perdan, S., 2005. An integrated sustainability decision-support framework Part II: problem analysis. Int. J. Sustain. Dev. World Ecol. 12 (2), 112e131.

Badea, A.C., 2010. Energy Security Indicators, vol 4. Institute for Energy Security Unit of the Joint Research Centre within the European Commission.

Borenstein, S., 2002. The trouble with electricity markets: understanding California's restructuring disaster. J. Econ. Perspect. 16 (1), 191e211.

Busato, F., Gatto, A., 2019. Evidenze empiriche dai prezzi elettrici durante la crisi energetica californiana. Cattura del regolatore nel caso Enron? Moneta Credito.

Busato, F., Gatto, A., 2017. Cyclical behavior of electricity prices during Enron Manipulations: energy crises and regulation. In: Proceedings from the International Conference on Energy, Macroeconomics and Finance (ICEFM). Montpellier Business School, Montpellier, France.

Cherp, A., Jewell, J., 2010. Measuring energy security: from universal indicators to contextualized framework. In: Sovacool, B. (Ed.), The Routledge Handbook of Energy Security. Routledge, pp. 330e355.

Costantini, V., Gracceva, F., Markandya, A., Vicini, G., 2007. Security of energy supply: comparing scenarios from a European perspective. Energy Policy 35 (1), 210 e226.

de Figueiredo, M.C.B., Rodrigues, G.S., Caldeira-Pires, A., de Freitas Rosa, M., de Aragao, F.A.S., Vieira, V.D.P.P.B., Mota, F.S.B., 2010. Environmental performance evaluation of agro-industrial innovations-Part 2: methodological approach for performing vulnerability analysis of watersheds. J. Clean. Prod. 18 (14), $1376 \mathrm{e} 1385$.

Drago, C., Gatto, A., 2018. A robust approach to composite indicators exploiting interval data: the Intervalvalued Global Gender Gap Index (IGGGI). In: Advances in Gender and Culture Studies in Business and Economics. 4th IPAZIA Workshop on Gender Issues, 2018. Springer, Rome, Italy, ISBN 978-3-030-00335-7.

EC, 2001a. Towards a European Strategy for the Security of Energy Supply. European Communities.

EC, 2001b. Directive 2001/77/EC of the European Parliament and the Council of 27 September 2001 on the promotion of electricity produced from renewable energy sources in the internal electricity market. Off. J. Eur. Commun. L283/33. (Accessed 27 October 2001).

EC, 2003. Directive 2002/91/EC of the European parliament and of the Council of 16 december 2002 on the energy performance of buildings. Off. J. Eur. Commun. L1/65. (Accessed 4 January 2003).

EC, 2006. Directive 2005/89/EC of the European Parliament and of the Council of 18 January 2006 Concerning Measures to Safeguard Security of Electricity Supply and Infrastructures Investment. L33/22. (Accessed 4 February 2006).

Engemann, K.M., Kliesen, K.L., Owyang, M.T., 2011. Do oil shocks drive business cycles? Some US and international evidence. Macroecon. Dyn. 15 (S3), 498e517. 
ESMPAP, 2009. Country Energy Sector Vulnerability Assessments Program: Helping Countries Prepare an Effective Energy Sector Response. https://esmap.org/sites/default/files/esmap-

files/FINAL_CESVAP_Broch.pdf.

EU, 2011. Regulation No. 1227/2011, Regulation on Wholesale Energy Market Integrity and Transparency (REMIT).

FAO, 2016. Resilience Index Measurement and Analysis e RIMA II.

Frankenberger, T., Langworthy, M., Spangler, T., Nelson, S., Campbell, J., Njoka, J., 2012. Enhancing Resilience to Food Security Shocks.

Gatto, A., Busato, F., 2019. Defining, measuring and ranking energy vulnerability. CREATES Research Papers.

Gatto, A., 2020. A pluralistic approach to economic and business sustainability: A critical meta-synthesis of foundations, metrics and evidences of human and local development. Corporate Social Responsibility and Environmental Management. https://doi.org/10.1002/csr.1912.

Gatto, A., Drago, C., 2020a. A taxonomy of energy resilience. Energy Policy 136 (2020), 111007. https://doi.org/10.1016/j.enpol.2019.111007.

Gatto, A., Drago, C., 2020b. Measuring and modeling energy resilience. Ecol. Econ. https://doi.org/10.1016/j.ecolecon.2019.106527.

Gatto, A., Ferrari, M., Sadik-Zada, E.R., 2017. (2017). Is waste-to-energy an effective strategy to increase the resource efficiency of the economy? A panel data approach to Circular Economy in EU. In: AIQUAV 2017 Associazione Italiana per gli studi sulla Qualita della Vita. Italian Association for the Studies on Quality of Life (AIQUAV).

Ghisellini, P., Cialani, C., Ulgiati, S., 2016. A review on circular economy: the expected transition to a balanced interplay of environmental and economic systems. J. Clean. Prod. 114, 11e32.

Gnansounou, E., 2008. Assessing the energy vulnerability: case of industrialised countries. Energy Policy 36 (10), 3734e3744.

Gupta, E., 2008. Oil vulnerability index of oil-importing countries. Energy Policy 36 (3), 1195e1211.

International Bank for Reconstruction and Development, The World Bank, 2017. State of Electricity Access Report.

International Energy Agency andWorld Bank, 2017. Sustainable Energy for All 2017-Progress toward Sustainable Energy. World Bank, Washington DC.

Joint Research Centre-European Commission, 2008. Handbook on Constructing Composite Indicators: Methodology and User Guide. OECD publishing.

Kendell, J., 1998. Measures of Oil Import Dependence.

Khan, I., 2019. Power generation expansion plan and sustainability in a developing country: a multi-criteria decision analysis. J. Clean. Prod. 220, 707e720. 
Kruyt, B., van Vuuren, D.P., De Vries, H.J.M., Groenenberg, H., 2009. Indicators for energy security. Energy Policy 37 (6), 2166e2181.

Markham, J.W., 2018. Regulating the "too big to jail" financial institutions. Brooklyn Law Rev. 83 (2), 12.

Meadows, D.H., Meadows, D.L., Randers, J., Behrens, W.W., 1972. The Limits to Growth. New York, vol. 102, p. 27.

Morrow, N., Salvati, L., Colantoni, A., Mock, N., 2018. Rooting the future; on-farm trees' contribution to household energy security and asset creation as a resilient development pathwaydevidence from a 20-year panel in rural Ethiopia. Sustainability 10 (12), 4716.

Nardo, M., Saisana, M., Saltelli, A., Tarantola, S., Hoffman, A., Giovannini, E., 2005. Handbook on Constructing Composite Indicators.

Patlitzianas, K.D., Doukas, H., Kagiannas, A.G., Psarras, J., 2008. Sustainable energy policy indicators: review and recommendations. Renew. Energy 33 (5), 966e973.

Percebois, J., 2007. Energy vulnerability and its management. Int. J. Energy Sect. Manag. 1, 51e62.

Ren, J., Dong, L., 2018. Evaluation of electricity supply sustainability and security: multi-criteria decision analysis approach. J. Clean. Prod. 172, 438e453.

Sovacool, B.K., 2011. Defining, measuring, and exploring energy security. In: Sovacool, B.K. (Ed.), The Routledge Handbook of Energy Security, pp. 1 e42.

Sterling, A., 2014. From Sustainability, through Diversity to Transformation: towards More Reflexive Governance of Technological Vulnerability.

UN, RES/70/1, 2015. Transforming Our World: the 2030 Agenda for Sustainable Development.

U.S. Department of Energy Office of Energy Assurance, 2002. Vulnerability Assessment MethodologyElectric Power Infrastructure. Washington, DC.

Wang, D., Zheng, J., Song, X., Ma, G., Liu, Y., 2017. Assessing industrial ecosystem vulnerability in the coal mining area under economic fluctuations. J. Clean. Prod. 142, 4019e4031.

Winzer, C., 2012. Conceptualizing energy security. Energy Policy 46, 36e48.

World Bank, 2017. World Development Indicators 2017. Washington, DC. ( World Bank. https://openknowledge.worldbank.org/handle/10986/26447. License: CC BY 3.0 IGO.

World Energy Council, 2008. Europe's Vulnerability to Energy Crises. 


\begin{tabular}{|c|c|c|c|c|c|c|c|c|}
\hline & & $\begin{array}{c}\text { A) } \\
\text { Electricit } \\
\text { y Access }\end{array}$ & $\begin{array}{l}\text { B) Energy } \\
\text { Intensity }\end{array}$ & $\begin{array}{l}\text { C) } \\
\text { Energy } \\
\text { Import } \\
\text { s }\end{array}$ & $\begin{array}{l}\text { D)Renewab } \\
\text { le Energy } \\
\text { Consumpti } \\
\text { on }\end{array}$ & $\begin{array}{l}\text { E) Energy } \\
\text { Consump } \\
\text { tion }\end{array}$ & $\begin{array}{l}\text { F) Fuel } \\
\text { Export }\end{array}$ & $\begin{array}{c}\text { G) } \\
\text { Renewable } \\
\text { Electricity } \\
\text { Output }\end{array}$ \\
\hline \multirow[t]{7}{*}{ Correlation } & A) Electricity Access & 1,000 & 371 &,- 140 &,- 258 &,- 380 &,- 187 & 007 \\
\hline & B) Energy Intensity & 371 & 1,000 &,- 115 &,- 259 & ,217 &,- 123 &,- 008 \\
\hline & C) Energy Imports &,- 140 &,- 115 & 1,000 &,- 049 &,- 203 & ,797 & ,008 \\
\hline & $\begin{array}{l}\text { D)Renewable Energy } \\
\text { Consumption }\end{array}$ &,- 258 &,- 259 & -049 & 1,000 &,- 042 &,- 190 & 701 \\
\hline & E) Energy Consumption &,- 380 & ,217 &,- 203 &,- 042 & 1,000 &,- 113 & 028 \\
\hline & F) Fuel Export &,- 187 &,- 123 & 797 &,- 190 &,- 113 & 1,000 &,- 217 \\
\hline & G) Renewable Electricity Output & 007 &,- 008 & ,008 & 701 & 028 &,- 217 & 1,000 \\
\hline \multirow{7}{*}{$\begin{array}{l}\text { Sign. (one } \\
\text { tail) }\end{array}$} & A) Electricity Access & & ,000 & ,046 & ,001 & ,000 & 012 & ,469 \\
\hline & B) Energy Intensity & ,000 & & ,084 & ,001 & ,004 & ,070 & ,463 \\
\hline & C) Energy Imports & , 046 & ,084 & & 279 & ,007 & ,000 & 462 \\
\hline & $\begin{array}{l}\text { D)Renewable Energy } \\
\text { Consumption }\end{array}$ & ,001 & ,001 & ,279 & & ,309 & 011 & ,000 \\
\hline & E) Energy Consumption & ,000 & ,004 & ,007 & 309 & & ,088 & ,367 \\
\hline & F) Fuel Export & 012 & ,070 & ,000 & ,011 & 088 & & ,004 \\
\hline & G) Renewable Electricity Output & ,469 & 463 & 462 & ,000 & ,367 & 004 & \\
\hline
\end{tabular}

Table 1 - Correlation matrix

\begin{tabular}{|c|c|c|c|c|c|c|c|}
\hline & $\begin{array}{c}\text { A) } \\
\text { Electricit } \\
\text { y Access }\end{array}$ & $\begin{array}{l}\text { B) Energy } \\
\text { Intensity }\end{array}$ & $\begin{array}{c}\text { C) } \\
\text { Energy } \\
\text { Import } \\
\mathrm{s}\end{array}$ & $\begin{array}{c}\text { D) Renewable } \\
\text { Energy } \\
\text { Consumptio } \\
n\end{array}$ & $\begin{array}{c}\text { E) Energy } \\
\text { Consumptio } \\
n\end{array}$ & $\begin{array}{l}\text { F) Fuel } \\
\text { Export }\end{array}$ & $\begin{array}{c}\text { G) Renewable } \\
\text { Electricity } \\
\text { Output }\end{array}$ \\
\hline A) Electricity Access & 1,921 & $\begin{array}{ll}-666 \\
-6\end{array}$ & ,297 & 825 & 1,006 & ,183 &,- 587 \\
\hline B) Energy Intensity &,- 666 & 1,447 &,- 098 & 307 &,- 559 & 092 &,- 163 \\
\hline C) Energy Imports & ,297 &,- 098 & 3,221 & 322 & ,534 & $-2,583$ &,- 830 \\
\hline $\begin{array}{l}\text { D)Renewable Energy } \\
\text { Consumption }\end{array}$ & 825 & 307 & 322 & 2,644 & ,485 & ,091 & $-1,853$ \\
\hline E) Energy Consumption & 1,006 &,- 559 & ,534 & 485 & 1,630 &,- 123 &,- 428 \\
\hline F) Fuel Export & 183 & 092 & $-2,583$ & 091 &,- 123 & 3,253 & ,666 \\
\hline G) Renewable Electricity Output &,- 587 &,- 163 &,- 830 & $-1,853$ &,- 428 & ,666 & 2,464 \\
\hline
\end{tabular}

Table 2 - Inverse correlation matrix 


\begin{tabular}{llr} 
Kaiser-Meyer-Olkin measure of sampling adequacy &, 435 \\
\hline Bartlett's sphericity test & Chi-sq. Approx. & 387,667 \\
\cline { 2 - 3 } & gl & 21 \\
\cline { 2 - 3 } & Sign. &, 000 \\
\hline
\end{tabular}

Table 3 - KMO and Bartlett's tests

\begin{tabular}{lr|r} 
& \multicolumn{1}{c|}{ Starting } & \multicolumn{1}{|c}{ Extraction } \\
\hline A) Electricity Access & 1,000 &, 872 \\
\hline B) Energy Intensity & 1,000 &, 892 \\
\hline C) Energy Imports & 1,000 &, 920 \\
\hline D) Renewable Energy Consumption & 1,000 &, 878 \\
\hline E) Energy Consumption & 1,000 &, 900 \\
\hline F) Fuel Export & 1,000 &, 906 \\
\hline G) Renewable Electricity Output & 1,000 &, 904 \\
\hline
\end{tabular}

Note: Extraction method: principal component analysis

Table 4 - Communalities

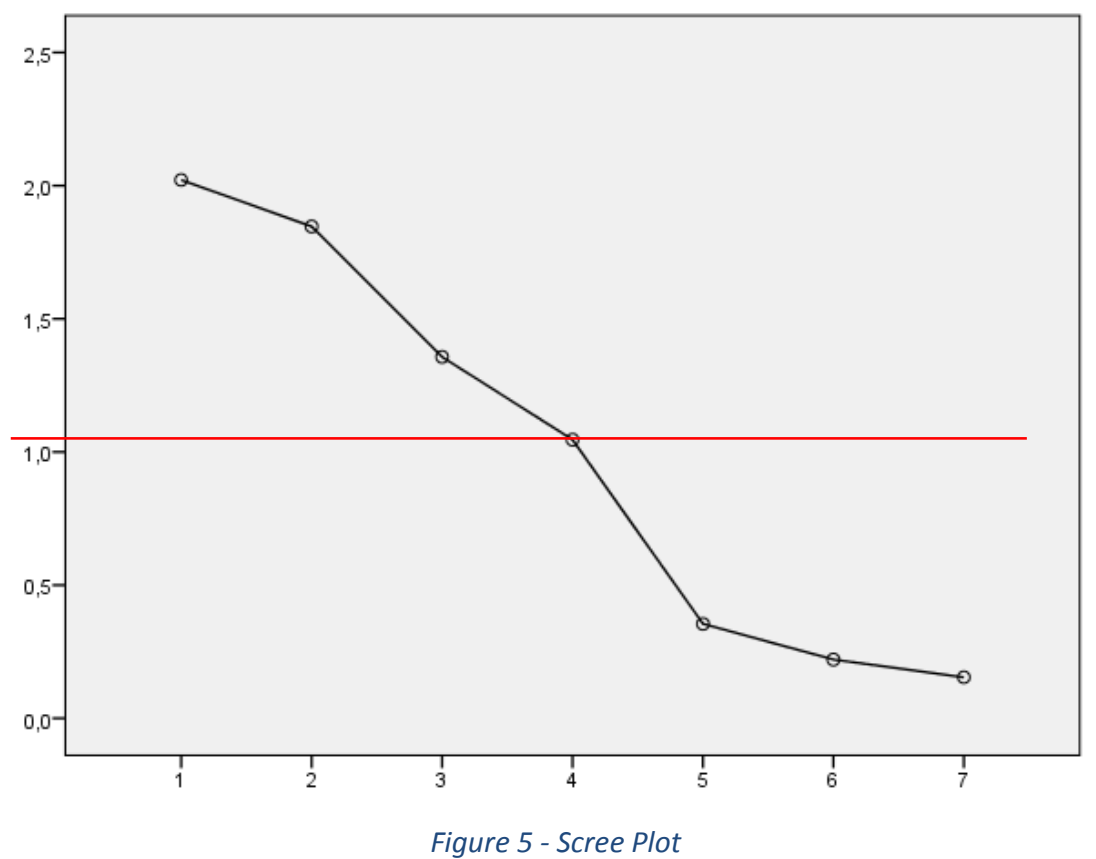

Note: the $y$ axis denotes the eigenvalue, while the $x$ axis denotes the component number 


\begin{tabular}{lr|r|r|r}
\hline A) Electricity Access &,- 133 &,- 593 &, 698 &, 127 \\
\hline B) Energy Intensity &,- 175 &,- 591 &, 014 &, 715 \\
\hline C) Energy Imports &, 801 &, 353 &, 182 &, 347 \\
\hline D) Renewable Energy Consumption &,- 466 &, 785 &, 190 &, 091 \\
\hline E) Energy Consumption &,- 241 &,- 019 &,- 834 &, 381 \\
\hline F) Fuel Export &, 892 &, 223 &, 002 &, 244 \\
\hline G) Renewable Electricity Output &,- 509 &, 596 &, 323 &, 430 \\
\hline
\end{tabular}

Extraction method: principal component analysis

4 components extracted.

Table 5 - Components matrix

\begin{tabular}{|c|c|c|c|c|c|c|c|c|}
\hline & & $\begin{array}{c}\text { A) } \\
\text { Electricity } \\
\text { Access }\end{array}$ & $\begin{array}{l}\text { B) Energy } \\
\text { Intensity }\end{array}$ & $\begin{array}{l}\text { C) Energy } \\
\text { Imports }\end{array}$ & $\begin{array}{c}\text { D) Renewabl } \\
\text { e Energy } \\
\text { Consumptio } \\
n\end{array}$ & $\begin{array}{c}\text { E) Energy } \\
\text { Consumptio } \\
n\end{array}$ & $\begin{array}{l}\text { F) Fuel } \\
\text { Export }\end{array}$ & $\begin{array}{c}\text { G) } \\
\text { Renewable } \\
\text { Electricity } \\
\text { Output }\end{array}$ \\
\hline \multirow{7}{*}{$\begin{array}{l}\text { Correlation } \\
\text { reproduced }\end{array}$} & A) Electricity Access & $872^{a}$ & ,474 &,- 145 &,- 259 &,- 491 &,- 219 &,- 006 \\
\hline & B) Energy Intensity & ,474 & ,892 &,- 098 &,- 314 & ,314 &,- 114 & ,049 \\
\hline & C) Energy Imports &,- 145 &,- 098 & $920^{a}$ &,- 030 &,- 219 & 879 & ,010 \\
\hline & $\begin{array}{l}\text { D) Renewable Energy } \\
\text { Consumption }\end{array}$ &,- 259 &,- 314 &,- 030 & $878^{a}$ &,- 027 &,- 218 & ,806 \\
\hline & $\begin{array}{l}\text { E) Energy } \\
\text { Consumption }\end{array}$ &,- 491 & ,314 &,- 219 &,- 027 & $900^{a}$ &,- 128 & ,006 \\
\hline & F) Fuel Export &,- 219 &,- 114 & 879 &,- 218 & -128 & $906^{a}$ &,- 216 \\
\hline & $\begin{array}{l}\text { G) Renewable } \\
\text { Electricity Output }\end{array}$ &,- 006 & ,049 & 010 & ,806 & ,006 &,- 216 & ,904a \\
\hline \multirow[t]{7}{*}{ Residual b } & A) Electricity Access & &,- 103 & 005 & ,001 & 111 & 032 & ,012 \\
\hline & B) Energy Intensity &,- 103 & &,- 016 & ,055 &,- 097 &,- 009 &,- 057 \\
\hline & C) Energy Imports & ,005 &,- 016 & &,- 019 & ,016 &,- 081 &,- 002 \\
\hline & $\begin{array}{l}\text { D)Renewable Energy } \\
\text { Consumption }\end{array}$ & 001 & ,055 &,- 019 & &,- 015 & 028 & -105 \\
\hline & $\begin{array}{l}\text { E) Energy } \\
\text { Consumption }\end{array}$ & 111 &,- 097 & 016 &,- 015 & & 015 & ,022 \\
\hline & F) Fuel Export & 032 &,- 009 &,- 081 & ,028 & , 015 & &,- 001 \\
\hline & $\begin{array}{l}\text { G) Renewable } \\
\text { Electricity Output }\end{array}$ & 012 &,- 057 &,- 002 &,- 105 & 022 &,- 001 & \\
\hline
\end{tabular}

Extraction method: principal component analysis

Communalities reproduced

The residuals are computed among the correlations observed and reproduced. There are $7(33,0 \%)$ non-redundant residuals with absolute values greater than 0,05 . 
Component

\begin{tabular}{|c|c|c|c|c|}
\hline & \multicolumn{4}{|c|}{ Component } \\
\hline & 1 & 2 & 3 & 4 \\
\hline A) Electricity Access &,- 184 &,- 093 &,- 716 &, 563 \\
\hline B) Energy Intensity &,- 056 &,- 068 & ,097 & ,935 \\
\hline C) Energy Imports & ,954 & ,052 &,- 077 &,- 037 \\
\hline D)Renewable Energy Consumption &,- 087 & ,888 & ,047 &,- 281 \\
\hline E) Energy Consumption &,- 146 &,- 019 & 908 & ,232 \\
\hline F) Fuel Export & ,930 &,- 182 & ,026 &,- 082 \\
\hline G) Renewable Electricity Output &,- 037 & ,942 &,- 010 & 120 \\
\hline
\end{tabular}

Extraction method: principal component analysis

Rotation method: Varimax with Kaiser normalization.

Convergence rotation run in 5 iterations.

Table 7 - Rotated components matrix

\begin{tabular}{lr|r|r|r} 
Component & \multicolumn{1}{l|}{1} & \multicolumn{2}{l|}{2} & \multicolumn{1}{l|}{3} \\
\hline 1 &, 852 &,- 488 &,- 097 &,- 162 \\
\hline 2 &, 325 &, 722 &, 194 &,- 580 \\
\hline 3 &, 103 &, 318 &,- 932 &, 141 \\
\hline 4 &, 397 &, 375 &, 291 &, 786 \\
\hline
\end{tabular}

Extraction method: principal component analysis

Rotation method: Varimax with Kaiser normalization.

Table 8 - Component transformation matrix 


\section{Appendix B - pillar-based country profiles}

Hereby are sketched the ten best and ten worst world performers in terms of energy vulnerability, according to the seven GEVI pillars presented in the text, while offering an additional and detailed perspective on the information just presented in Figure 1.
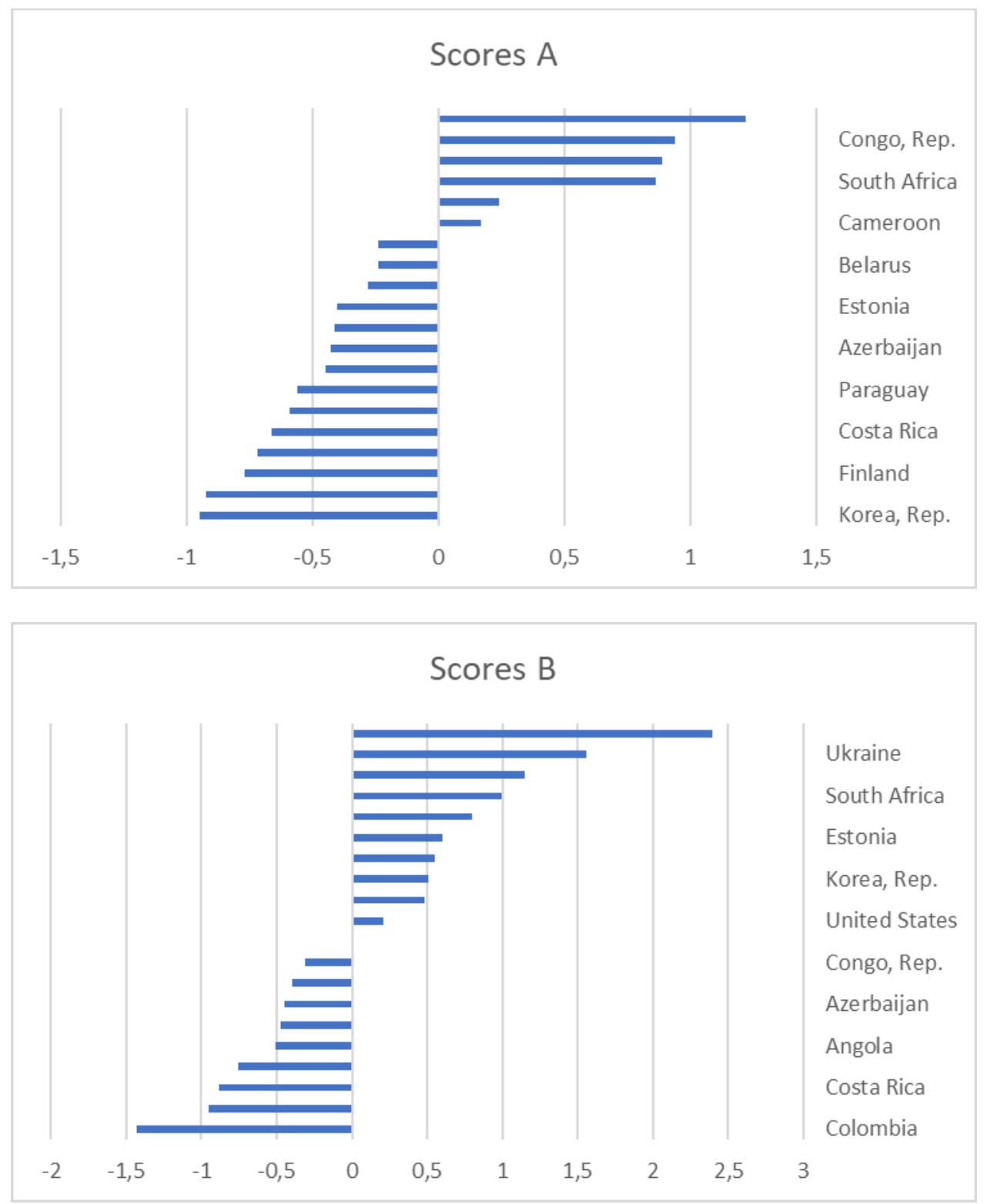

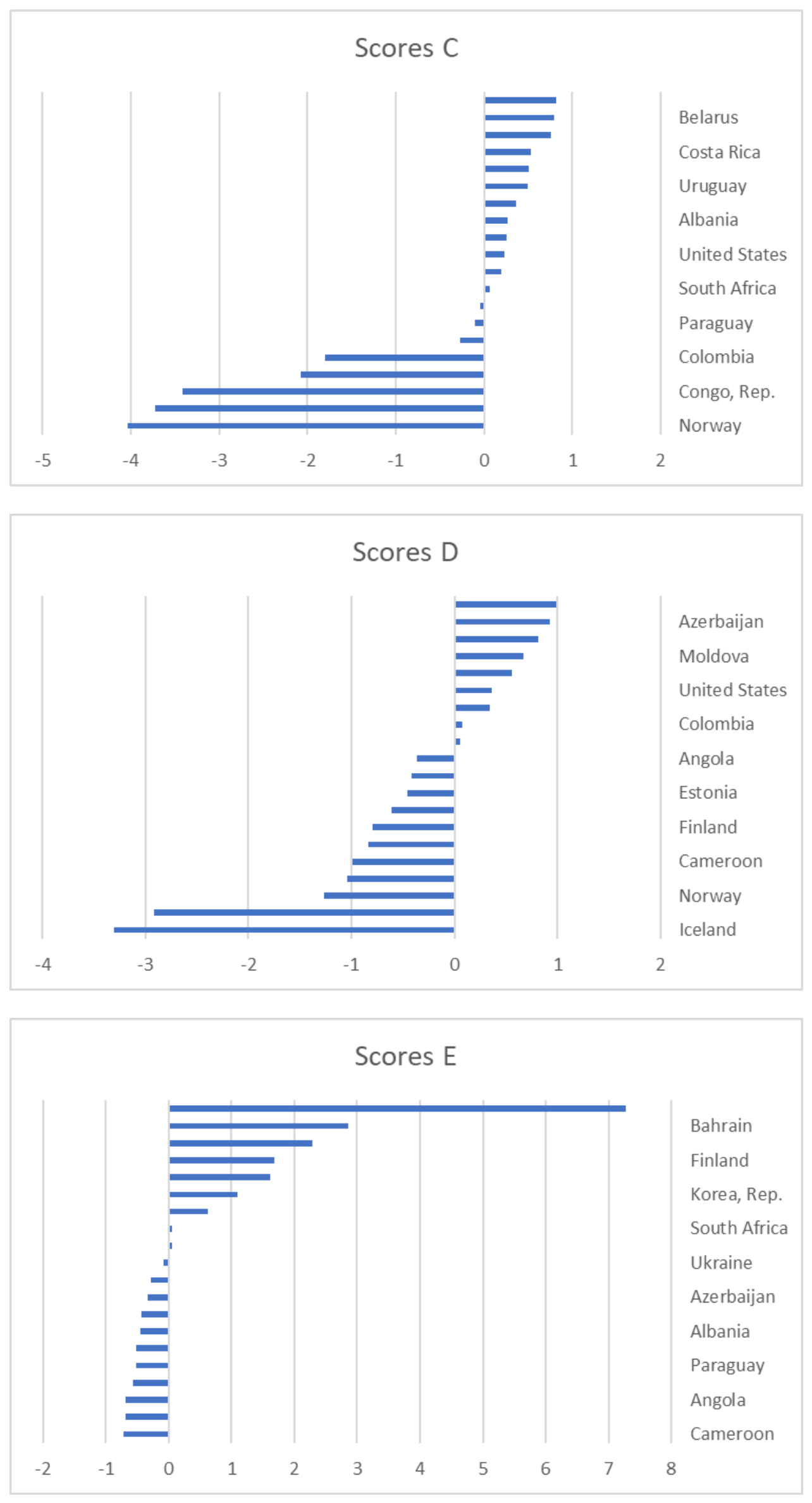

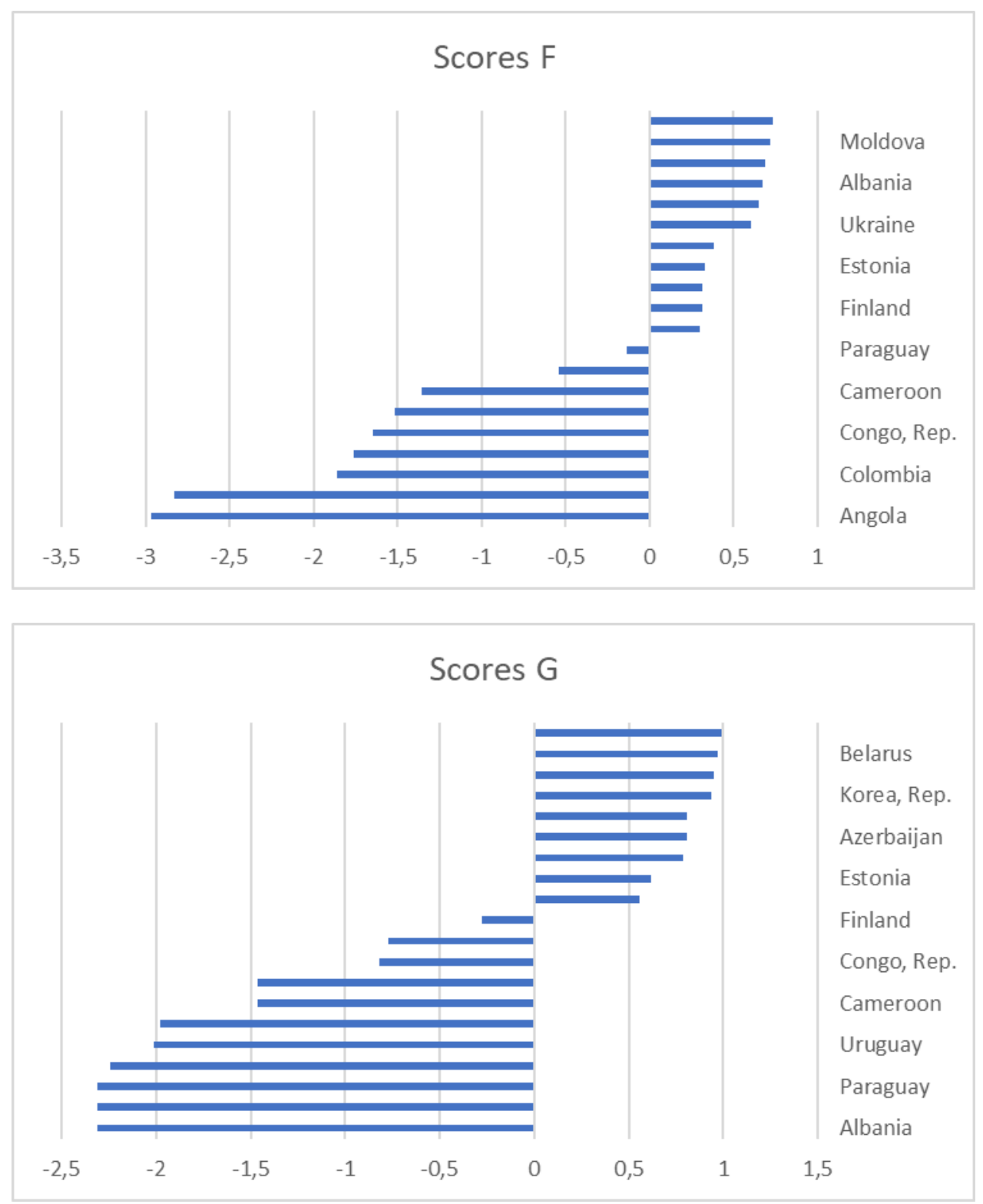


\section{Appendix C - pillar-based country profiles}

Below are sketched the ten best and ten worst world performers in terms of energy vulnerability, according to the seven GEVI pillars presented in the text, while offering an additional and detailed perspective on the information just presented in Figure 2.
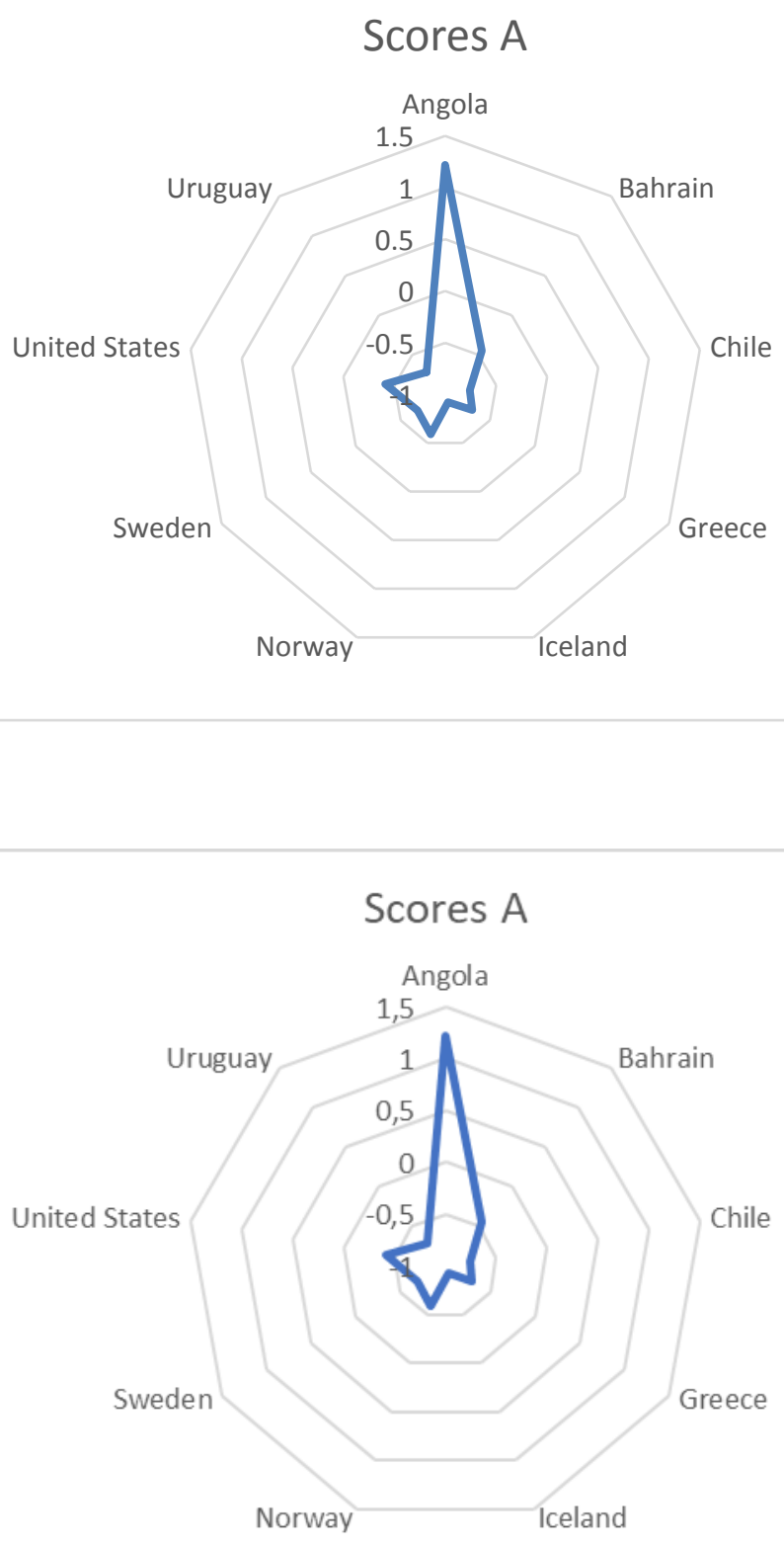

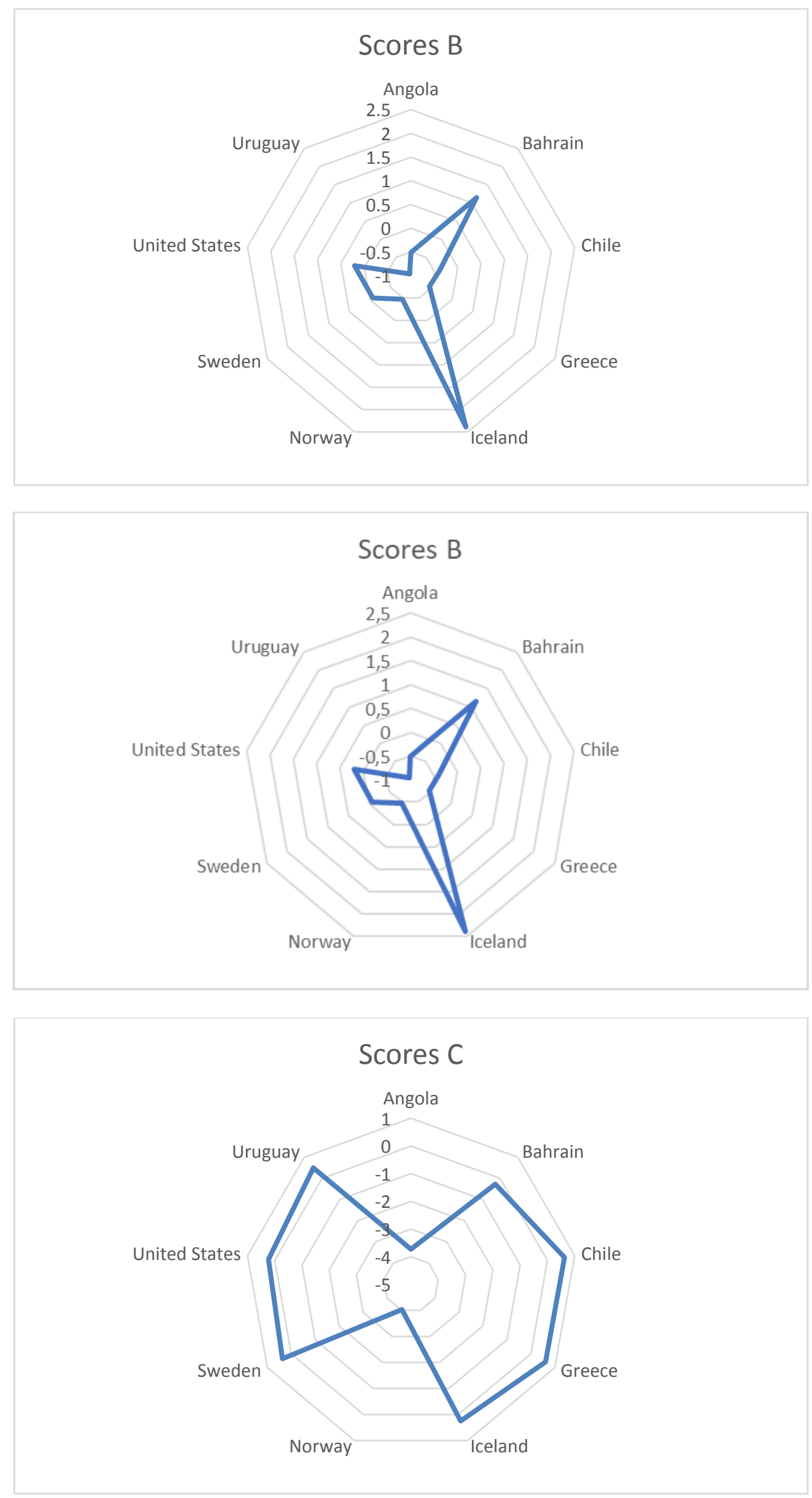

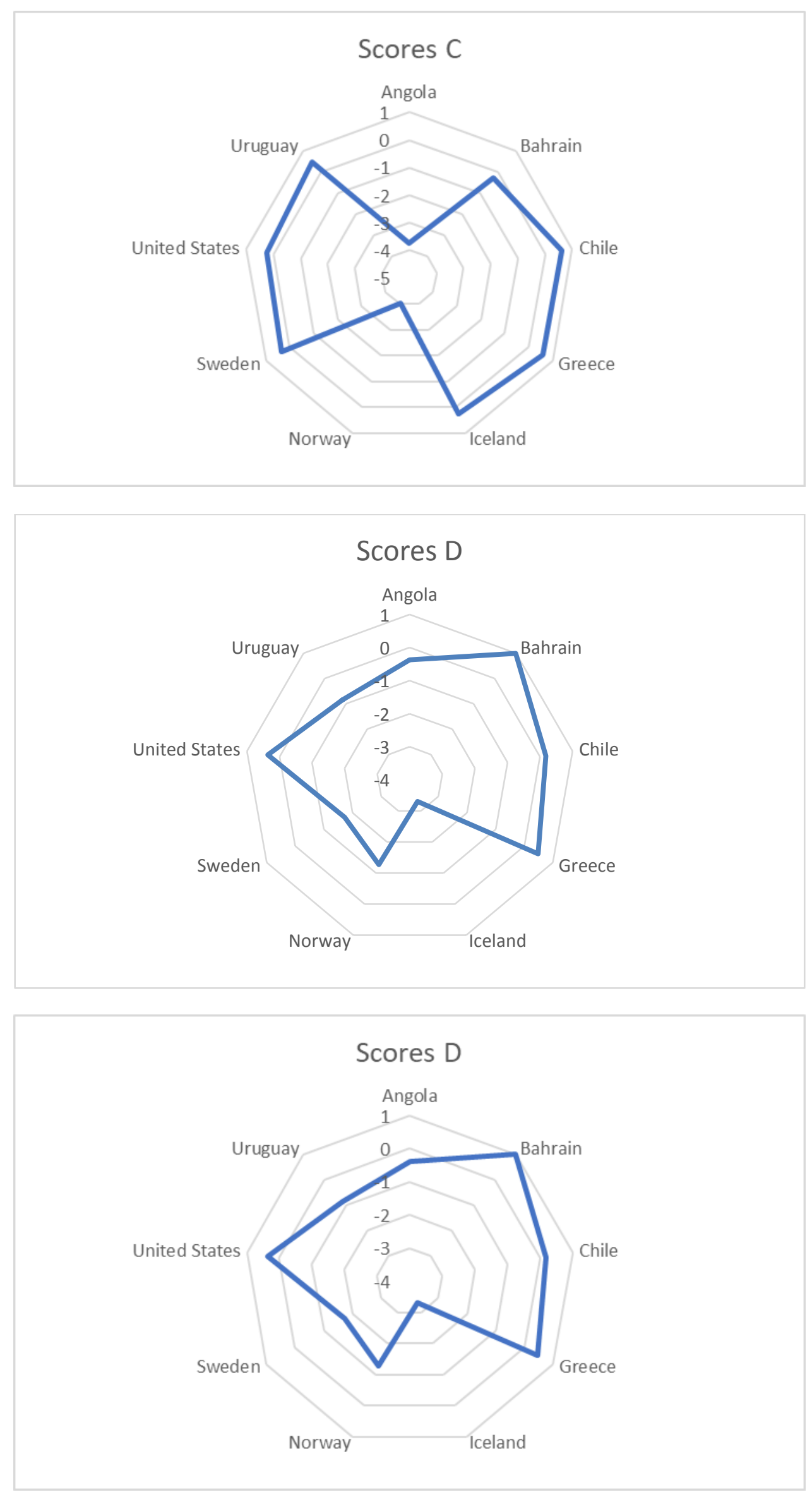

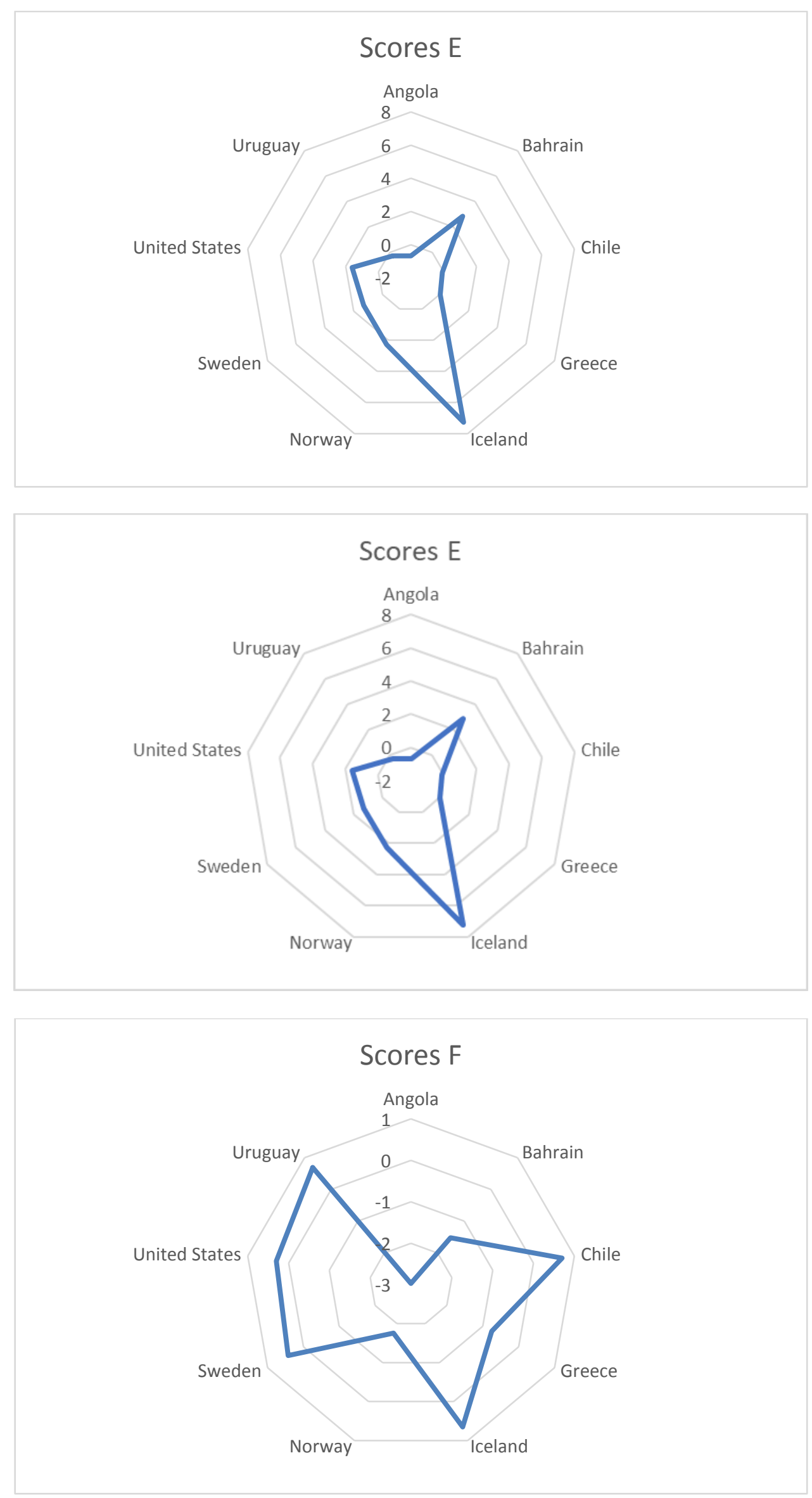

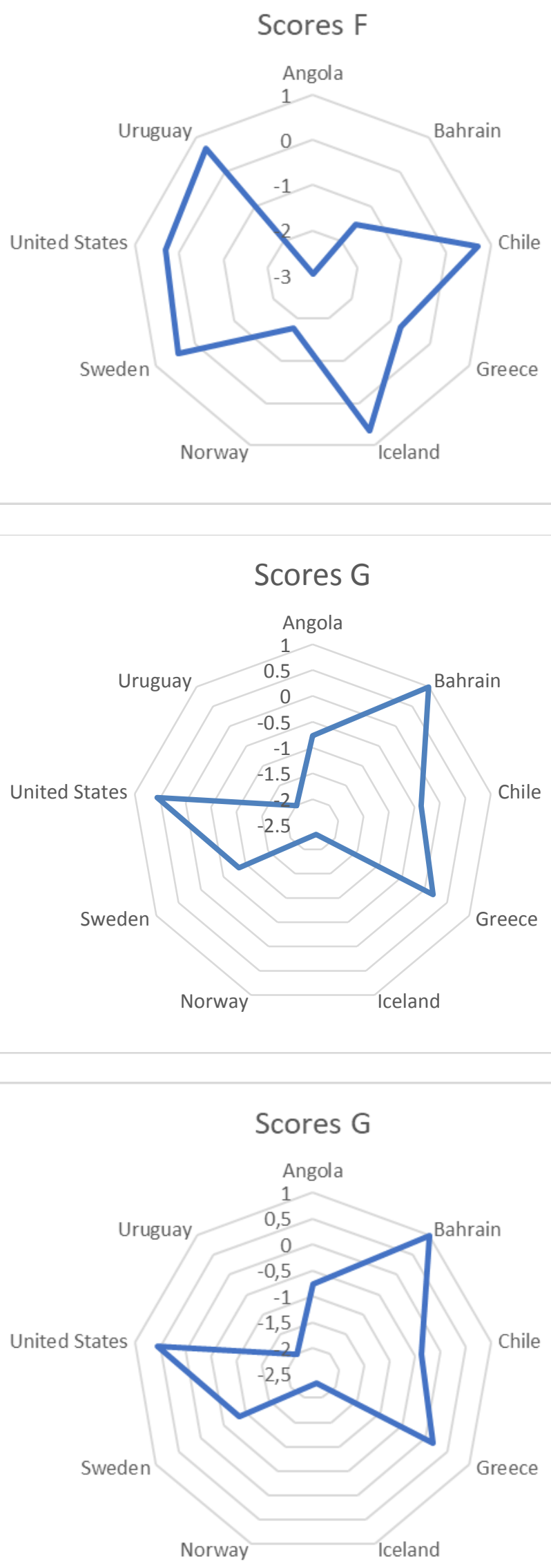